\title{
MERLÍ: MESTRE DO DISCURSO E DA DESCONSTRUC̣ÃO DA ESCOLA. UMA ANÁLISE DO SERIADO ESPANHOL A PARTIR DA PSICANÁLISE E EDUCAÇÃO
}

\author{
DOUGLAS EMILIANO BATISTA ${ }^{*}$ \\ ORCID: https://orcid.org/0000-0001-5345-1575
}

RESUMO: Este artigo, com base nos estudos de Psicanálise e Educação e em suas concepções de linguagem simbólica (Simbólico), sujeito da enunciação, narcisismo (Imaginário), alienação e separação, e ainda mestria da linguagem, pretende analisar o principal personagem da série espanhola Merlí, o professor de filosofia homônimo que leciona no Ensino Médio. Tal análise é revestida de interesse posto que Merlí encarna um ideal de docência contemporâneo. Merlí, de acordo com este artigo, se posiciona como o "mestre" do discurso, além de desconstruir as regras da escola a fim de emancipar seus jovens discípulos das relações de poder que ocorrem em sala de aula. O artigo propõe que a posição narcísica de Merlí torna difícil aos alunos a conquista de um lugar de enunciação. No mais, a desconstrução radical da escola talvez confunda as relações de poder entre professores e alunos com os laços simbólicos entre eles, laços que são essenciais à formação.

Palavras-chave: Merlí. Psicanálise e Educação. Docência e contemporaneidade.

\section{MERLI: MASTER OF SPEECH AND OF SCHOOL'S DECONSTRUCTION. AN ANALYSIS OF THE SPANISH SERIES ACCORDING TO PSYCHOANALYSIS AND EDUCATION}

ABSTRACT: This article, based on Psychoanalysis and Education and their notions of symbolic language (Symbolic), subject of enunciation, narcissism (Imaginary), alienation and separation, and language mastery, intends to analyze the main character of the Spanish series "Merli", a philosophy teacher of the same name teaching in High School. This analysis is relevant because Merlí represents a contemporary ideal of teaching. According to this article, Merlí assumes the position of The master of speech. Besides, he intends to deconstruct School rules to emancipate his young disciples from power relations that occur in the classroom. The article proposes that Merlís narcissistic position creates difficulties for students to conquer a place of enunciation. In addition, the radical School's deconstruction tends to confuse power relations between teachers and pupils with symbolic ties between them, ties that are essential to formation.

Keywords: Merlí. Psychoanalysis and Education. Teaching and contemporary.

'Universidade de São Paulo, Faculdade de Educação, São Paulo, SP, Brasil.

"Doutor em Educação pela FE-USP. Professor Contratado pela FE-USP e Coordenador e Professor do Mestrado em Educação da UNIB, Universidade lbirapuera. E-mail:< douglasemiliano@usp.br > . 


\section{INTRODUC̣̃̃O}

Merlí (2015) é um seriado televisivo que foi ao ar na Espanha pela primeira vez há três anos e que alcançou grande sucesso. A série contou também com uma expressiva audiência no Brasil.

Trata-se de uma produção da TV3, canal de televisão da Catalunha. Seus criadores são o diretor Eduard Cortés e o roteirista Héctor Lozano. Já a principal estrela é o ator Francesc Orella. Este interpreta o professor Merlí Bergeron Calduch. Tal personagem leciona filosofia em uma escola pública do Ensino Médio em Barcelona.

A série teve três temporadas e quarenta episódios ao longo de dois anos de produção, sendo que cada episódio foi contemplado com o nome de um filósofo cuja teoria inspirou os desdobramentos do enredo. Combinando certa dose de drama teen com lições que fazem lembrar os filósofos midiáticos, o seriado pretende tornar a filosofia palatável para o público em geral e para os estudantes em particular.

No presente artigo, pretende-se fazer uma análise do personagem Merlí a partir da Psicanálise e Educação. Tal análise é revestida de interesse na medida em que Merlí encarna um ideal de mestria bastante difundido. A hipótese aqui desdobrada é a de que Merlí talvez se posicione discursivamente como o mestre da palavra perante seus alunos, posicionamento que implicaria certos efeitos de fascinação no que toca a estes últimos. Ademais, Merlí se apresentaria como um desconstrutor de regras escolares. Isto é, Merlí não apenas encantaria (para o bem e para o mal) seus jovens discípulos por meio das lições de filosofia, como buscaria subverter a instituição escolar por considerá-la datada e instrumentalizada pelo mercado e pelo poder.

De certa forma, Merlí posiciona discursivamente os jovens escolares como discípulos no campo filosófico, mas ele, na suposta condição de mestre onipotente do discurso, gera dificuldades para que eles se desalienem dessa posição e conquistem um lugar de enunciação, isto é, uma posição simbólica de sujeito. Por outro lado, Merlí se recusa a posicionar discursivamente os jovens como discípulos da instituição escolar, e isso em virtude de reduzir a escola às relações de poder que a atravessam. Ora, a questão é que a alienação, ${ }^{1}$ na posição de discípulo, é também uma condição para que o jovem, ao se separar posteriormente desse lugar em que é situado, venha a assumir o ônus e o bônus que a enunciação enquanto sujeito implica. Em outras palavras, a conquista de um lugar simbólico de sujeito exige uma alienação prévia por parte dos jovens na posição discursiva de aluno, sem a qual eles não chegariam a dispor do repertório necessário para assumir sua singular enunciação. 
Segundo a conjectura deste artigo, Merlí parece tornar difícil o deslocamento que vai da alienação à separação no tocante aos jovens. É que embora Merlí os aliene inicialmente na malha do discurso filosófico, seu discurso tão envolvente dificultaria a desejável desalienação posterior por parte dos jovens. E no que concerne a posicioná-los como alunos de uma instituição escolar, Merlí, como foi asseverado, evita fazê-lo em razão do modo como concebe a escola, ou seja, como uma instituição regrada a partir da lógica da dominação. Merlí, portanto, gostaria de desinstitucionalizar a escola radicalmente, uma vez que nela reinaria, sem contradição, toda sorte de relações de subjugação.

Com vistas a tratar dessas questões, inicio esboçando um quadro descritivo do seriado do qual farão parte algumas análises preliminares. Não pretendo, entretanto, ser exaustivo quanto ao quadro. Na sequência, procurarei analisar a posição discursiva de Merlí (posição que, estando atravessada pela "mestria do discurso", incrementaria as vicissitudes inerentes à formação de seus alunos). Por fim, abordarei a pretensão de Merlí de levar a cabo a radical desinstitucionalização escolar.

\section{ACERCA DO SERIADO}

O personagem Merlí é, de certa forma, um professor liberal que concebe a escola como uma prisão, a sala de aula como uma cela e o professor como um carcereiro. Por conta disso, Merlí apreciaria desconstruir a escola sob a justificativa de que se trata de uma instituição arruinada, desinteressante e disciplinar. Seus colegas professores, a seus olhos, não seriam senão "abelhas operárias" cuja enfadonha labuta se destinaria a conformar os jovens de extração social modesta a ocupar postos de trabalho mal remunerados. Enfim, atravessada de ponta a ponta por relações de poder, a escola seria uma instituição arcaica cujo destino é produzir nos jovens indiferença, tédio ou ódio.

Em face dessa visada, resta então a Merlí adotar uma posição radicalmente alheia à cultura escolar. O professor espanhol tenta quebrar assim quase todas as regras da escola com vistas a provocar a reflexão emancipatória de seus alunos em relação a um sistema de ensino tido como estruturalmente opressivo, tradicionalista e autoritário. Para tanto, Merlí não poupa recursos. E tal como aquela mosca que aparece ziguezagueando freneticamente sobre livros de filosofia na abertura do seriado, Merlí adota então uma linha de ação docente imprevisível, caótica e até chocante. Desse modo, ele não apenas atordoa os demais professores supostamente tão enviscados ao pretenso marasmo da vida escolar como ainda fascina 
os alunos ao apresentar-lhes concepções alegadamente mais frescas e transgressoras do que a juventude mesma seria capaz de engendrar.

Mas nosso subversivo mestre de sessenta e poucos anos tem outro traço em comum com seus alunos. Merlí, logo no primeiro episódio da série, sofre um despejo domiciliar que o obriga a morar com sua mãe. Simultaneamente a isso, ele assume a guarda de seu filho adolescente (fato esse que se deve à ex-esposa de Merlí se mudar de Barcelona para Roma). Eis que o professor espanhol, portanto, assume os cuidados de seu filho ao mesmo tempo em que passa a morar com a própria mãe. Por fim, vendo-se premido a trabalhar, Merlí encontra então o emprego de professor em uma escola pública (a mesma em que seu filho estuda).

Disposto a conferir vida e juventude a uma instituição que considera obsoleta, Merlí quebrará as regras escolares assim como as não escolares: ele fará com que seus alunos - que chamará de "peripatéticos" - assistam a algumas das aulas de filosofia caminhando pela escola e, logo, ficando longe da sala/cela de aula. Quanto a esse aspecto, vale frisar que, em si mesma, tal metodologia não implica qualquer desmantelamento da dita "boa organização escolar". A bem da verdade, sair da sala de aula para retornar a esse espaço (cuja dignidade é igualada apenas por aquela das bibliotecas escolares) pode ser bastante fecundo. O único risco envolvido no emprego de tal metodologia repousa, todavia, na possibilidade de muitos professores decidirem adotá-la ao mesmo tempo, o que geraria um impasse de mobilidade pelas dependências de qualquer escola que conte com alguns milhares de alunos. De fato, talvez fosse mais fácil ser peripatético nos jardins do Liceu do que nas escolas da modernidade (as quais acolhem, frequentemente, um contingente populacional muito expressivo). De toda forma, sair da sala de aula pode mesmo ser relevante para a formação do alunado, mas, sobretudo, quando se retorna a ela a fim de se refletir acerca da experiência realizada para além dos indispensáveis limites físicos e dos estruturantes contornos simbólicos de uma classe.

Merlí, no mais, desprestigiará a grade curricular de filosofia por concebê-la como um "gradil” e não como uma sistematização menos ou mais consistente, organizada e falível dos conhecimentos acumulados nesse campo. Ora, o professor espanhol talvez desconsidere que, se por um lado, "os pré-requisitos normais de um currículo padrão” (ARENDT, 2000, p. 232) restringem determinado campo epistêmico, eles, por outro, o organizam. Ou seja, tais prérequisitos criam balizas simbólicas para que os não iniciados em tais conhecimentos possam aceder a estes. 
Todavia, apesar de Merlí desconsiderar o currículo de filosofia, há que se reconhecer que o professor espanhol se mostra muito astuto ao se valer educacionalmente dos acontecimentos contingentes que ocorrem na vida escolar. É que de um modo totalmente improvisado, porém bastante consistente, ele se serve das vicissitudes do acaso para ensinar a seus alunos a respeito de tal ou qual filósofo. E Merlí assim o faz sempre que a reflexão deste ou daquele filósofo interpela exatamente aquilo que de inesperado emergiu no quotidiano escolar. ${ }^{2}$

$\mathrm{Na}$ esteira desse procedimento, pode-se asseverar também que Merlí não é um tecnocrata. Isto é, Merlí não está preocupado com o dito desenvolvimento das competências ou habilidades dos alunos, ou tampouco se ocupa com a aplicação da Teoria da Resposta ao Item em suas provas. Ou seja, o endereçamento de Merlí aos alunos não é tecnicista. Pelo contrário, ao ofertar conhecimentos, Merlí se implica subjetivamente com tal oferta e, assim sendo, tal ensino não é anônimo. Ou em outros termos: a maneira como Merlí anima os conhecimentos de filosofia suscita nos alunos uma autêntica demanda epistêmica. Isto é, Merlí, de fato, posiciona os alunos como discípulos no campo da filosofia. E isso, decerto, não é inócuo na formação deles. No entanto, Merlí - segundo a hipótese deste artigo - não apenas torna muito onerosa a desalienação dos alunos em virtude do modo egoico ou narcísico como exerce a mestria, senão que se recusa também a posicioná-los como alunos da instituição escolar. Isso, tampouco, é inócuo. De todo modo, a questão é que, no final das contas, a formação dos alunos talvez acabe sendo posta em xeque por tais razões.

Mas para além de quebrar as regras escolares, Merlí não hesita em quebrar outras tantas normas. $\mathrm{Na}$ esteira disso, ele, por exemplo, flerta com algumas das mães de alunos, assim como toma parte nos mexericos juvenis com vistas a estreitar sua relação com Gina, a mãe do aluno Gerard. Merlí também revela impudicamente segredos de seu filho (tal como o fato de Bruno fazer balé). Ou ainda: Merlí não hesita em se passar por outro professor, Eugeni (docente esse que ministra aulas de Catalão). É que Eugeni viria a ser o tutor doméstico de um aluno que deixou de frequentar a escola por sofrer de agorafobia. E Merlí, por sua vez, se passou por Eugeni para se tornar o tutor desse aluno. Merlí, por sinal, critica acidamente Eugeni por este ser um tradicionalista e detestar os alunos (razão pela qual Eugeni não seria, aos olhos de Merlí, um bom tutor para o aluno agoráfobo). A bem da verdade, Eugeni é um docente odiado pelos alunos e chamado por estes de "Hitler", enquanto Merlí acabou se tornando o professor mais popular da escola durante a primeira e a segunda temporadas do seriado. 
Bem, encerrando aqui esse esboço de quadro descritivo (que em parte já é analítico), passo a abordar a hipótese do narcísico exercício da mestria por Merlí. Posteriormente, procurarei tratar das possíveis razões pelas quais Merlí se propõe a quebrar toda sorte de regras escolares.

\section{MERLÍ: O MESTRE DO DISCURSO?}

É razoável afirmar que se encontra assentado para os estudos de Psicanálise e Educação que formar professores é formar mestres (cf. LAJONQUIÈRE, 2011). Entretanto, isso de modo algum significa que o professor, uma vez formado, encarne o pretenso "mestre da palavra e da linguagem". Afinal, a formação docente, ao contrário de fazer do professor o "mestre do discurso, faz dele sujeito da mestria do discurso". E, sendo assim, aquilo que faculta que alguém, ao longo de certo tempo de formação, se desloque do lugar de "aspirante a professor" para o de "um mestre" é a sujeição ao saber inconsciente que opera em certo campo docente. De mais a mais, é pela mesmíssima razão que se pode nomear o professor de "sujeito de ensinar" e, logo, o aluno, de "sujeito de aprender".

Vale frisar que o emprego do termo "sujeição" se dá aqui na medida em que o "aspirante a professor" deve inicialmente se alienar ao conjunto dos enunciados próprios a certo campo de conhecimentos, e isso para que, algum tempo depois, a disrupção subjetiva venha a dar lugar às enunciações daquele que passa a ser admitido como um docente em meio a outros. Tais enunciações de um mestre colocarão em ato a singularidade da apreensão dos enunciados compartilhados por determinado coletivo profissional.

Em suma: "um mestre" não é "O mestre", mas sim "sujeito da mestria" que se articula em torno de um campo constituído de saberes inconscientes e de conhecimentos públicos.

No caso de Merlí, talvez haja indícios de que ele, por vezes, encarne "O mestre" mais do que "um mestre" sobredeterminado pelo fio do discurso.

É que embora Merlí não deixe de ensinar aos jovens tal como "um mestre" que se sujeitou inconscientemente aos discursos dos filósofos, ele, por outro lado, parece algumas vezes servirse narcisicamente da malha discursiva da filosofia para cativar os estudantes. Além disso, Merlí, em algumas circunstâncias, aplica tais enunciados filosóficos a fim de solucionar todo tipo de impasses menos ou mais corriqueiros que acometem sua vida pessoal, familiar, 
amorosa ou profissional. Dessa forma, seria o gozo utilitarista dos conhecimentos e enunciados de filosofia - mais do que seu usufruto desiderativo - que estaria em questão aí.

Em outras palavras, Merlí, por um lado, usufrui do discurso filosófico enquanto um fim em si mesmo ao ensinar a seus alunos (o que, por sinal, oferece um claro testemunho de sua sujeição a ensinar, isto é, de sua sujeição à mestria da linguagem). Decerto, é a partir desse ensino (no qual a filosofia é posicionada como um fim valoroso por si mesmo mais do que como um meio útil) que Merlí suscita claros efeitos formativos nos estudantes.

Mas, por outro lado, Merlí também parece tomado por uma paixão instrumental pela filosofia, paixão que eventualmente o leva a manipular de forma mitômana alguns de seus alunos, familiares, amantes e até colegas professores. Eis um exemplo de como Merlí, servindo-se de uma aplicação filosófica, goza do outro enquanto meio para lograr fins:

No episódio da primeira temporada intitulado Maquiavel, foi, ao pretensamente aplicar a filosofia desse filósofo, que Merlí furtou na escola uma prova em branco (uma avaliação da disciplina de Catalão). Seu objetivo era entregá-la a seu filho, Bruno. De fato, Bruno vinha sendo objeto de uma mesquinha perseguição por parte do professor de Catalão, Eugeni. Este atormentava Bruno em virtude, sobretudo, de uma forte rivalidade narcísica com Merlí. E nosso anti-herói, que não hesitou em furtar a prova, titubearia, contudo, quanto a entregála a Bruno, reconhecendo assim o malfeito em questão. Merlí - tendo agido como o senhor do discurso e o mestre da ação ao furtar a prova - acabou optando, ao cabo de tudo, por entregá-la à própria mãe, exortando esta última a jamais ceder a prova para Bruno.

Dito e não feito, a mãe de Merlí deu de bandeja a prova para o neto, sendo que Bruno compartilhou a mesma com Pol, um colega de sala por quem Bruno era apaixonado... ${ }^{3}$ Ambos os estudantes obtiveram, dessa forma, notas tão elevadas quanto inusitadas na disciplina de Catalão e, assim, despertaram uma suspeita por parte de Eugeni. Este então desconfiou de Merlí (que foi o único professor a ter estado sozinho com o maço de provas na sala dos professores). Merlí, com isso, se deu conta do risco de ser acusado pelo furto e também afastado da escola, receio que ele manifestou para a própria mãe. Ela, em face de tais acontecimentos, tentou então convencer o neto Bruno a assumir o furto da prova... Mas pior ainda: quem assumiu o furto foi outro aluno de Merlí, Joan. Este o fez para poupar o fascinante professor dos dissabores de uma justa punição. 
Bem, diante de tais acontecimentos, penso ser inevitável indagar se eles não encenariam uma montagem perversa destinada a safar os mais velhos - bem como a imolar os mais novos - no altar da instrumentalização do outro, isto é, no altar de uma alienação a partir da qual a possibilidade de separação se tornaria muito difícil. E em tal hipótese, o mais grave seria que Merlí, ao "aplicar" a filosofia de Maquiavel, teria tentado então solucionar - de uma forma "doméstica" e antiética (no caso, furtar a prova para o "bem" de seu filho) - uma vicissitude escolar que deveria ter sido eticamente enfrentada na escola. E mais: quando tal cálculo gozoso falhou, Merlí recorreu à sua mãe a fim de ter a "pele" salva por Bruno, seu filho, seu aluno e também seu bode expiatório. Bruno, com razão, recusou esse papel (muito embora não tenha recusado o outro "papel", isto é, a prova em branco). Mas, no fim de tudo, Joan se ofereceu ao sacrifício e, desse modo, Merlí saiu ileso.

Em suma, quanto a essa conjectura: uma vez posicionado como mandachuva do discurso filosófico, Merlí acabou despontando aos olhos de não poucos alunos como um "herói mitológico" (designação essa formulada pela própria mãe de Merlí a respeito de seu filho). Eis que o professor estaria, assim, a gozar de ser um Merlin da nova geração, isto é, um mago, um conselheiro, um insubstituível profeta para os mais novos. De mais a mais, vale lembrar, no que diz respeito à hipótese aqui apresentada, que o sobrenome "Bergeron" provém de "berger", palavra a qual significa "pastor"; e "Calduch" faz referência a "conduco" em latim (isto é, "guiar", "pastorear"). Bem, ao que parece, Merlí não seria do tipo que larga fácil o cajado. E, assim, o professor espanhol, em dadas circunstâncias, acabaria incrementando as vicissitudes inerentes à inversão da demanda educacional por parte de seus alunos.

Por hipótese, a posição prevalentemente egoica de Merlí lhe imporia então uma considerável dificuldade para se eclipsar como mestre de seus alunos. E, como se sabe, o eclipse a posteriori ${ }^{4}$ por parte do professor é o que suscita que o aluno se desaliene e, assim, conquiste uma posição enunciativa no campo da linguagem. Desse modo, a inflação narcísica - ou seja, o empoderamento egoico - não favoreceria, no caso de Merlí, a assunção de uma posição simbólica de sujeito por parte dos alunos (assunção essa que constitui o núcleo mesmo da formação educacional).

Em síntese: a hipotética primazia em gozar da filosofia mais do que usufruir dela não parece ter impedido Merlí de posicionar os jovens estudantes como discípulos no campo filosófico; todavia, tal 
primazia criaria obstáculos para a separação subjetivante por parte desses mesmos jovens. E, já no que diz respeito à indispensável alienação inicial dos mais novos na posição de alunos da escola, Merlí, provavelmente, nada queria saber dela, e isso pelas possíveis razões que explorarei a seguir.

\section{MERLÍ E A QUEBRA DAS REGRAS ESCOLARES}

Merlí parece, ao menos em certas circunstâncias, pertencer ao gênero dos mestres que pretendem se "autorizar" apenas de si mesmos; e isso tal como se o grande Outro, isto é, a linguagem simbólica, nada tivesse a ver com a referida "autorização" docente. Nesse sentido, podese supor que Merlí talvez seja um professor muito mais "empoderado narcisicamente" do que "autorizado simbolicamente". É que enquanto a autorização simbólica implica o Outro (posto que é preciso autorizar-se de si e ao mesmo tempo dos outros), a busca ávida pelo "empoderamento egoico" ou "narcísico" só pode degradar a relação com o Outro. Ou seja, a busca ávida pela certeza egoica ou narcísica (a certeza de si, de auto-identidade) debilita as relações de reciprocidade e, logo, a relação com o outro empírico (cf. IMBERT, 2001).

Talvez tenha sido em vista desse "empoderamento egoico" que Merlí anunciou em inúmeros episódios da série que "as regras existem para ser quebradas". E ele, de fato, as quebra repetidamente, a exemplo do que ocorre no primeiro episódio da segunda temporada, quando Merlí abre o ano escolar distribuindo sacos de pipoca na sala de aula para os alunos. Sob a justificativa de que assim como se come pipoca no cinema deve-se poder comê-la na sala de aula, Merlí quebra a norma que manda não comer em classe.

Pois bem, o que possivelmente está em jogo nisso é que se as regras, tal como quer Merlí, existem com a finalidade de ser quebradas, então talvez não existam regras e, logo, poderíamos todos viver um dia em um mundo sem limites, isto é, em um limbo amorfo e anômico. ${ }^{5}$

Merlí parece, algumas vezes, desconstruir as regras de um modo tão arbitrário quanto o eventual arbítrio que as instituiu. Todavia, ao quebrá-las dessa forma, Merlí corre o risco de levar a cabo a imaginarização da transgressão, reduzindo-a eventualmente a um procedimento repetitivo e banalizado. Talvez quase se trate de "quebrar as regras por quebrar". Ou seja, Merlí faria da quebra das regras a regra inquebrantável. Nesse sentido, "quebrar tudo" não se diferiria de "quebrar nada", e isso nos mesmos termos em que a onipotência não é senão o polo oposto da impotência em toda miséria neurótica. 
Outra conjectura pertinente, a partir disso, é que Merlí supõe que a margem de liberdade que nos cabe enquanto humanos decorreria automaticamente da ruptura das regras. Nessa hipótese, tudo se passaria então como se a vida subjetiva e a vida coletiva fossem possíveis em uma "condição humana absolutamente não normativa" (condição na qual a diferença e a assimetria entre professor e aluno, por exemplo, não fariam nenhum sentido). Embalado então nas possíveis ilusões de um educador progressista, Merlí admitiria que a modesta cota de autonomia possível seria fruto da supressão de toda moral instituída.

Outra coisa bastante distinta disso, porém, é o reconhecimento de que as regras, sendo imaginárias, podem e às vezes devem ser transgredidas, mas isso em nome do simbólico Espírito das Leis, e não em vista de um arbítrio pessoal ou coletivo. Segundo a perspectiva da Psicanálise, a transgressão das regras imaginárias (ou instituídas) só pode se dar no campo do Outro (Simbólico), posto que toda transgressão requer a sujeição psíquica à mestria da linguagem. Em suma, segundo a Psicanálise não haveria margem de liberdade humana - e, logo, não haveria possibilidade de transgressão ética (ou instituinte) da moral instituída - senão em face da sujeição à mestria da linguagem. Ora, sob tal perspectiva se faz razoável admitir que em um mundo privado da "Lei simbólica instituinte" e desguarnecido de "regras imaginárias instituídas" somente restaria uma liberdade totalmente amorfa, isto é, uma liberdade "fora do tempo e do espaço simbólicos" (DUFOUR, 2005, p. 27). Eis que se estaria aí em face da liberdade própria à estrutura psíquica da psicose.

Em síntese: sob o prisma aqui proposto, Merlí evitaria posicionar os jovens como alunos da instituição escolar, a fim de lhes franquear uma liberdade alegadamente incondicional, acima e além de quaisquer regras de comando e de poder, e isso como se a chamada relação professor/aluno não estabelecesse entre estes, também, vínculos simbólicos, isto é, um laço subjetivante no campo da palavra e da linguagem. Dessa forma, enquanto o ensino de conhecimentos de filosofia na escola emanciparia os alunos, a escola mesma, segundo Merlí, somente os condicionaria a obedecer e reproduzir as relações de dominação instituídas. Daí, portanto, que apenas a desconstrução total do dispositivo escolar redimiria os jovens escolarizados, e isso para que eles nunca fossem alienados, de saída, na posição de aluno.

\section{ALGUMAS (IN)CONCLUSÕES}

O modo como o roteirista e o diretor de "Merlí" posicionaram o professor espanhol nessa ficção talvez permita afirmar que o 
narcisismo deste é o que estaria na origem de seu suposto controle autoral do discurso e da ação e, logo, de um eventual gozo controlador. E essa possível pretensão em ser o mandachuva da palavra seria, ademais, um traço indissociável do voto imaginário de desconstruir cabalmente a instituição escolar para assim lançar professores e alunos no limbo de uma liberdade denominada aqui como anômica.

Eis, por sinal, a hipótese central com que trabalhei ao longo deste artigo, hipótese que não pretendo ter demonstrado cabalmente. A intenção, antes, foi a de sustentar uma crítica ao que talvez seja a posição discursiva prevalente no ensino de Merlí. Neste artigo eu pretendi também provocar algumas reflexões de interesse para o campo da educação a partir do que se passa no quotidiano da escola do seriado espanhol. Reconheço, decerto, os inevitáveis limites do recorte teórico deste artigo bem como a posição "estranhamente familiar" ou "familiarmente estranha" que a psicanálise guarda em relação à filosofia (e vice-versa). Entretanto, se a psicanálise tem algo de relevante a propor sobre um seriado que aborda o ensino de filosofia, isso talvez se deva a essa posição "estranha e familiar" ou "extima" (exterior e ao mesmo tempo íntima) em face da filosofia. Foi, pois, a partir desse lugar, que pretendi realizar uma crítica teoricamente fundamentada, mas também sui generis. Penso que essa posição "extima" da psicanálise oferece as condições de possibilidade para a análise em questão bem como enseja levar a cabo uma crítica que, possuindo rasgos singulares, contribua com a inacabável reflexão sobre o polêmico ensino de filosofia por parte de Merlí.

Vale insistir ainda - quanto à perspectiva provavelmente imperante no discurso de Merlí - que este não propõe, em termos escolares, algo semelhante a uma "instituição explodida ou estilhaçada" no sentido de Maud Mannoni (a saber, uma instituição que evitaria empedernir-se a despeito da inevitabilidade de tentar perdurar no tempo e no espaço). Merlí parece querer desterritorializar a escola até atingir suas mais profundas dobras e reentrâncias (nas quais o catalão julga pulsar toda forma de violência disciplinar).

Tal como é comum ocorrer aos educadores liberais, Merlí não se daria conta, segundo a conjectura aqui proposta, de que a desconstrução doque quer que seja ocorreria na e pela linguagem e, logo, a desconstrução não poderia saltar para fora do campo do Outro. Todavia, e mesmo que tal salto anômico seja impossível segundo a psicanálise, nem por isso o voto imaginário de desconstruir radicalmente a instituição escolar se torna inócuo. É que embora a estrutura da linguagem seja pressuposta em toda desconstrução, esta, uma vez imaginarizada (isto é, tornada onipotente), acaba incrementando as vicissitudes inerentes à sujeição à 
mestria da linguagem (ou seja, as vicissitudes inerentes à subjetivação), e isso no âmbito familiar e escolar.

Em outras palavras, uma "desconstrução total" confundiria como afirma Dufour (2005, p. 195) - a dominação sociopolítica (que é contingente) com a sujeição à mestria da linguagem (que é necessária), confusão na qual incorreria Merlí ao se recusar a alienar os jovens na posição de alunos. E ainda que a sujeição à linguagem seja condição de possibilidade para toda dominação, ela é também a condição de possibilidade para toda interpelação ética que venha a dissolver as dominações sociais, étnicas, políticas etc. Portanto, a desconstrução total da escola acabaria por jogar fora, com a água do banho, o bebê. Dessa forma, e no caso de estar correta a presente conjectura, seria imprescindível, assim, que a desconstrução das relações de poder na escola não viesse a degradar o laço simbólico entre professor e aluno.

Antes de encerrar esta reflexão, vale frisar uma vez mais que o seriado "Merlí" não é de modo algum monolítico. Ou seja, ele contém paradoxos férteis em termos educacionais. Sendo assim, não é sem razão que Merlí, no episódio oitavo da segunda temporada, tenha realizado pela primeira vez, em um diálogo revelador com Eugeni, uma autocrítica a respeito de ter se tornado o melhor amigo e confidente dos alunos. Nos termos de Merlí: "agora esses pirralhos vêm sempre chorar no meu ombro e me deixam todo babado". Bem, convido o leitor a rever tal episódio para que avalie se exagero ao afirmar que ocorre aí um arrefecimento imaginário (narcísico) de Merlí no que toca em ser o professor mais popular da escola... E quer isso tenha ocorrido por uma feliz coincidência ou por uma brilhante intuição do diretor, o fato é que o título desse episódio é "Freud"! Eis que Freud implica subjetivamente o professor com a educação!

Merlí, em tal episódio, parece dar testemunho de que a vida escolar, em parte, o transformou. Eisso o teria feito admitir que, na escola ou fora dela, todo jogo tem sua regra (tanto quanto a transformação das regras faz parte do jogo). Porém, a transformação das regras somente pode se dar na medida em que continue sendo possível jogar. Caso contrário, será fim de jogo, e ninguém mais poderá jogar com as palavras ou ser jogado por elas (o que remete à sujeição estrutural à linguagem)... Ao contrário, só restaria jogar fora os jogos de linguagem...

Em face disso, creio ser imprescindível que a desconstrução das relações de poder na instituição escolar não implique a dessimbolização do laço social na escola e, logo, a dessimbolização subjetiva de alunos e professores. E isso é fundamental no caso de que se deseje "não calar", isto é, no caso de se desejar poder (se) falar. De todo modo, haverá que se assumir, na esteira disso, o ônus e o bônus que o ato de falar certamente implica. 


\section{REFERÊNCIAS}

ARENDT, H. Entre o passado e o futuro. São Paulo: Perspectiva, 2000.

DUFOUR, D-R. A arte de reduzir as cabeças: sobre a nova servidão na sociedade ultraliberal. Rio de Janeiro: Cia. de Freud, 2005.

IMBERT, F. A questão da ética no campo educativo. Petrópolis: Vozes, 2001.

LAJONQUIÈRE, L. A mestria da palavra: isso duro de roer na formação de professores. In: Mrech e Pereira (Orgs.). Psicanálise, transmissão e formação de professores. Belo Horizonte: Fino Traço, 2011.

MERLÍ. Direção: Eduard Cortés, Produção: Héctor Lozano. Intérpretes: Francesc Orella, David Solans, Candela Antón e outros. Barcelona, Espanha: TV3, 2015. 03 temporadas, 40 episódios.

\section{NOTAS}

${ }^{1} \mathrm{O}$ termo alienação é empregado aqui em sentido psicanalítico, isto é, enquanto alienação ao Outro (ou seja, ao campo da palavra e da linguagem). A alienação ao Outro passa, é claro, pelo outro imaginário (ou empírico).

${ }^{2}$ Não pretendo erigir aqui uma visão monolítica sobre o personagem. Afinal, este encarna contradições educacionalmente fecundas e que podem ser analisadas a partir de múltiplas perspectivas teóricas. O que busco é legitimar uma visada a partir da Psicanálise e Educação, e na qual se reconhece a virtude de Merlí em lidar com as imprevisíveis emergências do Real.

${ }^{3}$ Bruno apaixona-se por Pol, assim como Merlí tomará Pol como um "aluno ideal” por este quebrar as regras da escola todo o tempo.

${ }^{4}$ Nosso tempo é marcado, desafortunadamente, por um "eclipse de antemão" por parte do mestre (cf. DUFOUR, 2005), isto é, por uma prévia demissão do ato educacional. E tudo isso em nome do suposto "protagonismo" e da pretensa "autonomia" do aluno.

${ }^{5}$ Não seria equivocada a afirmação de que há certo exagero na imagem que se traça de Merlí nesse parágrafo. Entretanto, como propõe Arendt, às vezes é preciso "exagerar [...] para aclarar um argumento” (2000, p. 232). A minha intenção não é outra nesse caso.

Submetido: 06/12/2018

Aprovado: 08/01/2019

Contato:

Rua Osíris Magalhães de Almeida, n. 652 Apto. 94C, Jd. Monte Kemel

São Paulo $|\mathrm{SP}|$ Brasil

CEP 05.634-020 